\title{
OJS

\section{GEOCENÁRIOS DIGITAIS: FUNDAMENTOS TEÓRICO E METODOLÓGICO PARA O ENSINO DA PAISAGEM}

\author{
Bruno Gomes de Araújo ${ }^{1}$, Antônio Virginio Martins Neto ${ }^{2}$ \\ 1 Universidade do Estado do Amazonas, Professor Adjunto da Universidade do Estado do Amazonas, E-mail: \\ gomesaux@gmail.com,Orcidid: https://orcid.org/0000-0001-6613-7040 \\ 2 Universidade Federal do Rio Grande do Norte, Mestre em Inovação em Tecnologias Educacionais, E-mail: \\ antonioneto_geo@hotmail.com, Orcidid: https://orcid.org/0000-0002-5617-2579
}

Artigo recebido em 17/12/2020 e aceito em 19/03/2021

\section{RESUMO}

As metodologias de ensino da Geografia escolar estão sendo ressignificadas pelas novas habilidades e competências ancoradas nas novas tecnologias da informação e comunicação. O desafio metodológico se revela frente à necessidade de atualização dos currículos da educação básica, adequação e inovação dos recursos didáticos da disciplina. O presente estudo tem como núcleo central a discussão teórica e didáticopedagógica dos Geocenários Digitais. Enquanto perspectiva metodológica de transposição didática, os Geocenários Digitais serão revelados como cenários geográficos personalizados, nos quais os fenômenos expressos na paisagem podem ser apresentados de forma multiescalar, tridimensional e em suas múltiplas conexões na superfície digital de um mapa geosoftware. O Geocenário Digital será discutido como projeto cartográfico customizado no Google Earth Pro, no qual o professor e o aluno, por intermédio de um texto didático, transpõem o fenômeno estudado para uma base cartográfica digital interativa geosoftware, inserindo objetos, incluindo fotos, vídeos, e dessa forma, esquematizando processos e conexões da paisagem. Por fim, destacamos a proposta dos Geocenários Digitais como ferramenta para o estudo gráfico-espacial da "paisagem na Totalidade-mundo"; perspectiva de análise fundamentada nas interconexões entre fenômenos sociais e físicos, que se expressam na lógica da reflexão sobre a configuração de diferentes paisagens pelo encadeamento de processos globais.

Palavras-chave: Geocenários Digitais; Geosoftware; Paisagem.

\section{DIGITAL GEOSCENARIOS: THEORETICAL AND METHODOLOGICAL FOUNDATIONS FOR LANDSCAPE TEACHING}

\section{ABSTRACT}

The teaching methodologies of school geography are being resignified by the new skills and competencies anchored in the new information and communication technologies. The methodological challenge is revealed in view of the need to update the curricula of basic education, adequacy and innovation of the teaching resources of the discipline. The present study has as its central nucleus the theoretical and didactic-pedagogical 
discussion of Digital Geoscenarios. As a methodological perspective of didactic transposition, Digital Geoscenarios will be revealed as customized geographic scenarios, in which the phenomena expressed in the landscape can be presented in a multiscale, three-dimensional way and in their multiple connections on the cartographic surface of a geosoftware. The Digital Geoscenario will be discussed as a customized cartographic project in Google Earth Pro, in which the teacher and the student, through a didactic text, transpose the phenomenon studied into an interactive geosoftware digital cartographic base, inserting objects, including photos, videos, and thus, schematizing processes and connections of the landscape. Finally, we highlight the proposal of digital geoscenarios as a tool for the graphic-spatial study of the "landscape in the Wholeworld"; perspective of analysis based on the interconnections between social and physical phenomena, which are expressed in the logic of reflection on the configuration of different landscapes by chaining global processes.

Keywords: Digital Geocenarians. Geosftware, Landscape.

\title{
GEOCENARIOS DIGITALES: FUNDAMENTOS TEÓRICOS Y METODOLÓGICOS PARA LA ENSEÑANZA DEL PAISAJE
}

\begin{abstract}
RESUME
Las metodologías de enseñanza de la geografía escolar están siendo reformuladas por las nuevas habilidades y competencias ancladas en las nuevas tecnologías de la información y la comunicación. El desafío metodológico se pone de manifiesto ante la necesidad de actualizar los currículos de educación básica, adecuación e innovación de los recursos didácticos de la disciplina. El presente estudio tiene como eje central la discusión teórica y didáctico-pedagógica de los Geocenarios Digitales. Como perspectiva metodológica de transposición didáctica, los Geoescenarios Digitales se revelarán como escenarios geográficos personalizados, en los que los fenómenos expresados en el paisaje se podrán presentar de forma multiescala, tridimensional y en sus múltiples conexiones en la superficie digital. de un mapa de geosoftware. El Geocenario Digital se discutirá como un proyecto cartográfico personalizado en Google Earth Pro, en el que el docente y el alumno, a través de un texto didáctico, trasladarán el fenómeno estudiado a un geosoftware de base cartográfica digital interactiva, insertando objetos, incluyendo fotos, videos, y desde de esa manera, delineando los procesos y las conexiones del paisaje. Finalmente, destacamos la propuesta de geoescenarios digitales como herramienta para el estudio gráfico-espacial del "paisaje en el mundo-totalidad"; perspectiva de análisis basada en las interconexiones entre fenómenos sociales y físicos, que se expresan en la lógica de la reflexión sobre la configuración de diferentes paisajes por la cadena de procesos globales.
\end{abstract}

Palabras clave: Geocenarios digitales. Geosoftware. Paisaje.

\section{INTRODUÇÃO}

As reflexões metodológicas dos Geocenários Digitais estão alicerçadas nas Geotecnologias presentes nos mais diversos softwares, entre eles, o Google Earth Pro. O seu potencial didáticopedagógico já foi analisado em outros estudos, porém, há muito o que ser explorado sobre a utilização sistemática e direcionada ao desenvolvimento de planos de ensino.

A customização de ambientes virtuais é uma estratégia que pode ser muito bem aproveitado para desenvolver o temário da geografia escolar e contribuir para o alcance de determinados objetivos de ensino, como ler, interpretar e representar fenômenos urbanos e ambientais. Essas e outras 
diretrizes se alinham à nova política educacional implementada pela Portaria $\mathrm{n}^{\mathrm{o}} 331$, de 5 de abril de 2018, que definiu competências gerais da educação básica.

A pesquisa partiu das inquietações em torno das novas perspectivas emitidas pela Base Nacional Comum Curricular (BNCC) que norteiam o ensino de geografia nas séries iniciais e as Geotecnologias. O documento anexou a cada uma das unidades temáticas um conjunto de objetivos de conhecimento e habilidades a serem construídas mediante diferentes proposições metodológicas (BRASIL, 2017).

Para além dos currículos conteudista, a importância de atualização dos currículos procedimentais é uma constante na geografia escolar. Isso justifica a experimentação das linguagens que contemplam o uso pedagógico das Geotecnologias. No estudo em questão, o Software Google Earth Pro será explorado na compreensão metodológica do modelo propositivo dos Geocenários Digitais.

A análise didático-pedagógica dos Geocenários Digitais destaca a contribuição para o estudo das interconexões dos fenômenos sociais e ambientais, guiando os objetivos de ensino e aprendizagem para além de uma análise restrita que não evidencia os sistemas que estruturam a Paisagem.

Assim, este artigo propõe um breve ensaio teórico, metodológico e conceitual sobre os Geocenários Digitais, considerando sua base teórica, "paisagem na totalidade-mundo" e os aspectos metodológicos que envolve sua aplicabilidade no processo de ensino e aprendizagem da geografia escolar.

A promoção da análise geossistêmica caracteriza, entre outros, os objetivos de aprendizagem guiados a partir da metodologia dos Geocenários Digitais, isto é, o conhecimento é produzido de forma colaborativa considerando a inserção e as relações entre os fenômenos desde o seu contexto imediato ao mais distante.

A representação dos fenômenos numa superfície cartográfica digital de um geosoftware proposta pelos Geocenários Digitais observa a construção do saber geográfico a partir do estudo das relações entre o local e o global, como também, a aquisição de habilidades que envolvem o aprimoramento do pensamento criativo e desenvolvimento de atividades colaborativas mediadas pelos geosoftwares.

Este artigo apresenta o estudo teórico-conceitual que fundamentou elaboração da metodologia do trabalho de campo na dissertação denominada Geocenários Digitais: uma abordagem inovadora para o ensino da Geografia de Martins Neto (2020). Além das categorias analíticas o estudo 
apresenta as análises da pesquisa de campo feito com professores do Ensino Fundamental através do curso de extensão divido em módulos, conforme demonstrado mais adiante.

A pesquisa de campo realizada a partir de um curso de extensão, objetivou apresentar os Geocenários Digitais aos professores da rede Municipal de Currais Novos-RN, contemplando o planejamento pedagógico e aplicação de diferentes temas da geografia, oportunizando a apropriação de uma nova linguagem para ambiente de ensino e aprendizado personalizado dos fenômenos geográficos à partir da Categoria de Paisagem.

Nos tópicos a seguir vamos discutir a Geografia e suas perspectiva didático metodológica mediada pelas Geotecnologias, bem como, os aspectos teóricos, conceituais e metodológicos dos Geocenários Digitais e suas interconexões com o fenômeno da Paisagem.

\section{A GEOGRAFIA ESCOLAR NA ERA DAS GEOTECNOLOGIAS}

Pensar na prática pedagógica atualmente é perceber o papel que os recursos tecnológicos têm representado nas modificações das formas do professor atuar em sala de aula. Inserir as novas tecnologias da comunicação e a informação é um desafio para o professor, oportunizando um espaço de ensinar e aprender.

Todavia, muitas das tecnologias digitais não são pensadas pedagogicamente, neste sentido, surge a expertise dos professores em agregar a sua prática docente esses recursos adaptando suas funcionalidades trazendo novos contornos ao planejamento didático como é o caso das Geotecnologias.

A Geografia Tecnológica, vertente do movimento de renovação da Geografia (MORAES, 2005), proporciona uma "nova" perspectiva de se pensar a Geografia escolar alinhada às tecnologias digitais, em especial as Geotecnologias e aos objetivos didáticos do professor. Assim as novas tecnologias da informação e comunicação:

[...] representa a capacidade criativa dos homens, através de técnicas e de situações cognitivas, representar situações espaciais e de localização para melhor compreender a condição humana. Assim, potencializar as tecnologias, significa ampliar as possibilidades criativas do homem, bem como ampliar os "olhares" à exploração de situações cotidianas relacionadas ao espaço geográfico, ao lugar da política, a representação de instâncias conhecidas e/ou desconhecidas, a ampliação das experiências e a condição de identificação com o espaço vivido (rua, bairro, cidade, estado, país). (BRITO E HETKOWISKI, 2010, p. 06). 
Considerando essa perspectiva, as Geotecnologias podem ser compreendidas como um recurso que aproxima a técnica ao espaço vivido, onde o sujeito é levado a conhecer e analisar os fenômenos geográficos de maneira participativa e crítica.

Neste sentido, busca a aproximar o conteúdo ao cotidiano e a imaginação do aluno e aos problemas do cotidiano são discutidos em sala de aula, aproximando os conteúdos à representação cartográfica e promovendo ações didáticas que sejam atrativas para os seus alunos, estimulando a criatividade e potencializando o envolvimento ativo dos alunos (CARVALHO, 2006).

É perceptível que as ações didáticas apoiadas nas Geotecnologias dentro das atividades escolares oferecem um material didático educacional relevante para se realizar uma interpretação mais profunda dos fenômenos geográficos, possibilitando a análise das transformações ocorridas no espaço geográfico em várias escalas e diferentes tempo, assim com, os aspectos físico-ambientais, sócio econômicos, além de estimular os professores a mediarem a proposta didática e atrair os seus alunos no envolvimento do cotidiano em sala de aula. Um bom exemplo são os recursos disponíveis em alguns dos geosoftwares como o Google Maps e Google Earth.

Por meio das Geotecnologias o professor pode adaptar sua prática pedagógica a realidade escolar e produzir um material digital que seja possível ser explorado dentro de sua prática docente, onde possa desenvolver uma aprendizagem que favoreça a reflexão, além do conhecimento tecnológico ao pedagógico.

Quando analisamos a Base Nacional Comum Curricular (BNCC) para o Ensino da Geografia, observa-se um direcionamento de proposta de currículo que contemple as Geotecnologias, iniciandose na alfabetização cartográfica, utilizando-se de fotografias, mapas, esquemas, desenhos, imagens de satélites, audiovisuais, gráficos, entre outras alternativas (BRASIL, 2017), possibilitando desta forma se apropriar destes elementos para entender os fenômenos geográficos, reforçando o papel das Geotecnologias como recursos que podem favorecer a compreensão das informações geográficas.

Em algumas pesquisas presentes na Base Digital de Teses e Dissertação no Brasil, como os trabalhos de Di Maio (2004), Nosoline (2011), Ferreira (2017) e Sousa (2018), é possível observar um esforço metodológico voltado para as Geotecnologias no contexto do ensino da Geografia e na perspectiva de formação de professores, evidenciando a relevância deste recurso na didática do professor. A tese de Hong (2012), por exemplo, apresenta uma formação continuada com professores do ensino básico no Estado do Colorado no Estados Unidos com o uso de Geotecnologias envolvendo a disciplina de geografia, apontando resultados satisfatórios com este recurso didático, contemplando fenômenos geográficos que muitas vezes não são expressos em livros didáticos. 
Muito embora estejamos tratando do potencial didático das Geotecnologias na prática pedagógica, vale ressaltar que temos um outro desafio a enfrentar que são as limitações quanto ao uso de computadores por parte dos professores, o que de certa maneira dificulta a aproximação das Geotecnologias com a prática docente. Neste sentido, devemos incentivar de forma constante a formação continuada de professores, a fim de minimizar o distanciamento entre as Geotecnologias e a atividade docente.

Assim, percebemos que as geotecnologias se apresentam como um recurso tecnológico que possibilita uma representação distinta dos fenômenos geográficos, aproxima a realidade cotidiana à proposta didática do professor por meio de suas ferramentas, tornando espaços imaginários/abstratos dos conteúdos expressos em livros didáticos mais próximos em nível de compreensão dos alunos.

\section{GEOCENÁRIOS DIGITAIS: PERSPECTIVAS TEÓRICAS, CONCEITUAIS E METODOLÓGICAS}

As transformações implementadas pelas novas tecnologias da informação e comunicação nas representações e linguagens da geografia escolar são irredutíveis e exigem proposições analíticas, e sobretudo, de novas instrumentações que renovem a metodologia de ensino da disciplina. Na esteira dessas novas tecnologias, assumem, cada vez mais importância, os aplicativos educacionais como a sincronização em nuvem, por exemplo, que permitem a portabilidade de projetos em diferentes dispositivos eletrônicos e novas possibilidades de ensinar e aprender geografia.

A didática do ensino da geografia no Brasil, historicamente apegada ao artifício das representações gráficas como desenhos, cartas mentais, croquis, maquetes, plantas e mapas, entre outras, é desafiada a aprimorar o currículo frente aos "geosoftwares" que valorizam novas habilidades de investigação e representação dos fenômenos geográficos.

O geosoftware ou software de cartografia corresponde a uma subcategoria das Geotecnologias, reconhecido sob duas tipologias distintas. A primeira tipologia é representada pelos Geosoftwares Fixos; são softwares de Sistemas de Informações Geográficas (SIGs) de acesso restrito ou livre, que permitem o desenvolvimento e edição de projetos cartográficos por um único usuário. Entre os mais populares, encontram-se os SIGs de instalação fixa como Arcgis, Qgis, Philcarto e Google Earth ou como denominou Longley (2013) de SIGs de desktops, onde o uso está restrito a um único computador e que não oferecem compartilhamento a outros usuários.

Na segunda tipologia se destacam os Geosoftwares em Rede. Estes operam na WEB (online) a partir de tecnologia em nuvem, com o intuito de armazenar dados geográficos e representar 
fenômenos no espaço de forma colaborativa, mediante a edição compartilhada de projetos entre vários usuários e em tempo real.

O aplicativo da Google conhecido como May Maps foi o geosoftware em rede pioneiro na tecnologia da edição compartilhada de cartografias digitais na web. Hospedado no Google Drive (nuvem da Google), o Google My Maps foi desenvolvido como mapa digital interativo, que permite a elaboração e tratamento de informações georreferenciadas através das delimitações de áreas, adição de marcadores georreferenciados, superposição de shapers, desenvolvimentos de rotas e medição de áreas.

Os geosoftwares oferecem, portanto, uma nova experiência pedagógica ao ensino da geografia escolar, bem como, na representação gráfico-espacial de fenômenos sociais e físicos. $\mathrm{O}$ desenvolvimento do raciocínio geográfico mediado pelos geosoftwares, como discutiremos no próximo tópico, possui ricos métodos que podem ajudar na construção do saber relacional, entre local/regional e local/global, como também para o desenvolvimento e aquisição de técnicas e habilidades que envolvem o manuseio de ferramentas digitais colaborativas vinculadas ao ciberespaço ${ }^{1}$ educacional.

É bem verdade que o tratamento didático-pedagógico dos recursos no ensino da Geografia na educação básica segue a tendência de colaboração entre o livro didático e os geosoftwares. A exemplo disso temos as plataformas educacionais desenvolvidas por diferentes selos editoriais que valorizam, para além do livro didático, conteúdos e avaliações exclusivamente digitais que remetem os alunos à outras plataformas interativas com recursos áudio visuais entre outros hospedados sites institucionais.

O desafio de atualizar o currículo da geografia escolar, conforme apontou Simelli (2018), passa inevitavelmente pela reconstrução de métodos e conceitos que atendam aos objetivos de ensino dos programas oficiais.

O desenvolvimento de metodologias que concorram efetivamente para o desenvolvimento do saber geográfico é tarefa que exige uma reflexão ativa das linguagens de ensino que conduzem a transposição didática de temas complexos que envolve a organização espacial da sociedade.

Neste sentido, observamos que os automatismos didáticos nada contribuem para o entendimento das categorias geográficas como Paisagem, Espaço, Território, Lugar e Região, para que essas não se percam conceitualmente na imensidão de temas e conteúdo dos currículos básicos.

\footnotetext{
${ }^{1}$ É o novo meio de comunicação que surge da interconexão mundial dos computadores. O termo especifica não apenas a infraestrutura material da comunicação digital, mas também o universo oceânico de informações que ela abriga, assim como os seres humanos que navegam e alimentam esse universo (Lévy, 1999. p. 17).
} 
Associado a isso, as limitações trazidas nos recursos gráficos e imagéticos como (fotos, mapas, tabelas, etc.) dificultam uma análise mais profunda e contextualizada de diferentes fenômenos e processos geográficos.

Essa problemática, portanto, é o foco de nossa proposição metodológica os Geocenários Digitais, que, em última análise, resulta da complementaridade entre texto didático e os geosoftwares. A referência teórico-conceitual dos Geocenários Digitais reside no estudo da Paisagem e dos processos que a constitui enquanto resultado de processos sociais e naturais.

A Paisagem, enquanto campo visual, é a síntese de processos ecológicos, um produto da relação entre sociedade e natureza, passível de análises objetivas e subjetivas. Noutro giro, a Paisagem também é investigada como estrutura formada; resultado de múltiplas conexões que se articulam numa infinidade de subestruturas e intencionalidades. A Paisagem apresenta variadas escalas, formas e funcionalidade que, ao serem relacionadas e dissociadas, constituem-se em regiões, territórios, áreas, geossistemas etc.

Para a leitura da Paisagem, as diretrizes estabelecidas na Base Nacional Comum Curricular BNCC $^{2}$ sugerem o desenvolvimento de habilidades e competências como o saber identificar, relacionar, descrever, explicar, articular, comparar e aferir escalas geográficas e cartográficas, entre outros, que formam a base do raciocínio geográfico. Em tais competências é imperativo o estímulo à elaboração de conteúdos procedimentais que capturem a participação efetiva do aluno.

Se tratando do estudo da Paisagem, temas e conteúdos trazidos nos livros didáticos pouco destacam metodologias participativas que possibilitem a representação espacial dos fenômenos pelo aluno. A Paisagem, longe de ser estática, acaba por ser representada nos livros didáticos como tal. Os recursos imagéticos em escala reduzida não lograram tanto êxito na representação dos processos associados à formação de uma dada Paisagem.

Sabemos que os elementos que compõem a Paisagem são dinâmicos e estão intimamente articulados, como também, apresentam diferentes formas e arranjos na superfície, e deste modo, é o resultando em variados cenários geográficos.

As Paisagens são, portanto, cenários, pois representam as diferentes tramas, estratégias e sistemas de domínios físicos do espaço geográfico. Os Geocenários Digitais, enquanto estratégia de

\footnotetext{
${ }^{2} \mathrm{Na}$ Base Nacional Comum Curricular evidenciam um conjunto de habilidades pertinentes aos objetivos do conhecimento geográfico, e que, portanto, orienta a didática do professor a priorizar conteúdos ativos como entre eles “[...] comparar modificações das paisagens nos lugares, (...) identificar as características das paisagens transformadas (...) medir distâncias na superfície pelas escalas gráficas e numéricas dos mapas. (BRASIL, 2017, p.385)
} 
ensino, têm o potencial de ajudar o aluno no descortinamento dessas variantes, como também, de ultrapassar a imprecisão da análise genérica dos processos físico-sociais da Paisagem.

Numa primeira aproximação conceitual, o Geocenário Digital pode ser concebido como a representação esquemática e multiescalar de processos, formas e funções da Paisagem na superfície cartográfica digital de um geosoftware. O Geocenário digital pode também ser entendido enquanto projeto educacional personalizado, onde o aluno, por intermédio de um geosoftware e texto didático, insere objetos, inclui fotos e vídeos, e dessa forma, pode simular processos e conexões da Paisagem numa base cartográfica digital interativa.

Os Geocenários Digitais como ferramenta didático-pedagógica possibilita a professores e alunos reproduzirem as conexões espaciais do fenômeno estudado e facilitam a montagem de cenários geográficos correspondentes ao conteúdo em cena, assim como, visualizá-los em variadas escalas e diferentes ângulos, mergulhando os estudantes numa experiência rica em detalhes que desvendam as articulações geográficas que estruturam a relação entre o local e o global.

Diferentemente das projeções estáticas das cartografias impressas, o mapa digital permite o leitor visualizar os sistemas de relações e processos que formam o contexto de diferentes paisagens. Através do recurso do Zoom Digital presente no Google Earth Pro, os estudantes podem empreender a análise do panorama espacial circundante à localidade representada.

Outros recursos ainda presentes neste software como: linhas, polígonos, projeções 3D e visualização em $360^{\circ}$ são algumas das novas possibilidades dispostas pelos geosoftwares e que precisam ser exploradas como conteúdos procedimentais e estratégias de estímulo à participação do aluno na investigação da Paisagem.

As Paisagens estudadas nos livros didáticos geralmente são recortes de uma ampla e gigantesca rede de conexões e processos e que fogem à análise dos professores e alunos, dada limitação de escala cartográfica veiculada às imagens trazidas nos livros didáticos.

$\mathrm{Na}$ perspectiva de objetivo de ensino, os Geocenários Digitais propõem organizar didaticamente o estudo do quadro da distribuição dos fenômenos na superfície cartográfica digital dos geosoftwares, a partir de uma metodologia ativa onde o aluno exercita suas habilidades de representação de fenômenos no espaço geográfico.

Enquanto objetivo de aprendizagem, a proposta busca mobilizar o aluno para compreender um estudo sistemático e aprofundado da Paisagem, consolidando, portanto, os processos de apreensão das semelhanças e individualidades dos lugares, e assim, ajudando o desenvolvimento da interpretação geográfica na composição de mosaicos terrestres em diferentes escalas. 
Quando consideramos os potenciais dos Geocenários Digitais, vislumbramos que o estudo da Paisagem em toda sua complexidade se torna possível de ser realizada em sala de aula, visto que o problema da extensão e da comparação de áreas podem ser superados nas proposições metodológicas no ensino da Geografia.

A proposta do Geocenário Digital tem muito a contribuir para construção de habilidades de comparação, descrição e interpretação da Paisagem. Isso porque a metodologia tenta aproveitar o máximo de informações e detalhes das cartografias tanto digitais como tridimensionais que hoje são amplamente disponíveis nos sistemas operacionais em dispositivos móveis, para então renovar o currículo frente aos novos cenários geográficos.

Discutimos as perspectivas teórico conceituais dos Geocenários Digitais no ensino da Geografia e suas potencialidades para o estudo dos processos que estruturam a Paisagem geográfica. No próximo tópico, centralizaremos nossa análise na compreensão dos fundamentos procedimentais e didáticos-pedagógicos dos Geocenários Digitais, considerando sua adaptação às etapas no processo de ensino- aprendizagem dos alunos na geografia escolar e suas interconexões com os fenômenos da Paisagem.

\subsection{Geocenários Digitais: aspectos didáticos-pedagógicos e representação das interconexões dos fenômenos da Paisagem}

A perspectiva teórica e metodológica da geografia moderna sobre a interconexão de fenômenos para o reconhecimento das particularidades da superfície terrestre demarcou o campo de estudo da disciplina e fundamentou, a posteriori, o arcabouço geral dos objetivos de ensino da geografia escolar.

A discussão sobre as habilidades e competências que envolvem o raciocínio geográfico teve início nos currículos na segunda metade da década 1980. É importante lembrar que este momento ficou marcado pela dicotomia entre as correntes positivista e crítica, que, por conseguinte, induziu à impressão equivocada de que se tratava de correntes teórica-metodológicas irreconciliáveis e mutuamente excludentes.

No entanto, os manuais de ensino e diretrizes educacionais no final da década de 1980 reconheceram a relevância do auxílio de gráficos, tabelas e mapas na investigação crítica dos fenômenos físico e sociais, reafirmando, assim, a importância desses recursos para o desenvolvimento da análise radical da realidade. 
A interdependência entre as correntes veio contribuir para que a supervalorização metodológica fosse evitada nos textos didáticos e promoveu uma relação dialógica e harmônica entre as correntes geográficas teórico-quantitativista e radical crítica. As transposições didáticas dos conteúdos geográficos caminharam no sentido de manter alinhadas às perspectivas pedagógicas, para enfim, avançar no desvendamento do conjunto de sistemas de relações que se abrangem a história natural e humana na superfície terrestre.

Paralelo à reconciliação entre os dois polos epistemológicos, viu-se o esforço dos pesquisadores para hierarquizar temas e conceitos, a partir de estudos sobre os estágios cognitivos do aluno no entendimento dos processos no espaço geográfico. Grande parte dos pesquisadores brasileiros que se dedicaram ao estudo do ensino da geografia escolar, como Pontuschkas (2007) e Oliveira (2007), entre outros, encontraram na teoria da Epistemologia Genética do Espaço de Jean Piaget $^{3}$ os fundamentos pedagógicos para adaptar as metodologias de ensino da geografia escolar por faixas etárias nas séries iniciais.

Por conseguinte, na década de 1990, a teoria piagetiana das etapas de aprimoramento sensório-motor (relações topológicas) e representação do espaço (euclidianas) ajudaram na elaboração dos objetivos de ensino, organização do conteúdo e níveis de complexidade nos currículos da geografia no fundamental I e II. Os Parâmetros Curriculares Nacionais (PCNs), por exemplo, trouxeram essa perspectiva das relações topológicas nos primeiros ciclos ( $1^{\mathrm{a}}$ e $2^{\mathrm{a}}$ anos $)$ " [ [...] a partir de situações nas quais compartilhem e explicitem seus conhecimentos, o professor pode criar outras nas quais possam esquematizar e ampliar suas ideias de distância, direção e orientação" (BRASIL, 1998, p.19).

Apesar disso, a influência piagetiana na pedagogia da geografia escolar, conforme destacou Simelli (2018), acabou por promover a separação dos instrumentos metodológicos adotados em cada ciclo de ensino. Segundo a autora, de um lado, o método indutivo estimulava os alunos das séries iniciais a pensar o espaço do "particular para o geral", isto é, do concreto para o abstrato. Do outro, o método dedutivo conduzia os alunos no ensino médio a raciocinar o fenômeno do "geral para o particular", identificando a partir da escala global os elos de um sistema de relações espaciais da economia, da política e cultura, até suas formas mais elementares no espaço.

\footnotetext{
${ }^{3}$ Segundo Piaget, a cognição da criança para compreensão e representação das relações espaciais de localização dos objetos no espaço é desenvolvimento mediante raciocínio lógico-matemático que, por sua vez, se dá em diferentes etapas (topológicas, projetivas e euclidianas) para mais detalhes ver PIAGET, J. A epistemologia genética. Petrópoles: Editora Vozes, 1972.
} 
A epistemologia do espaço de Piaget sobre o reconhecimento das estruturas espaciais no contínuo de operações concretas foi transposta didaticamente pela relação com o imediato (bairro, rua, casa, escola) e fez predominar o método indutivo como pedra fundamental para elaboração de conteúdos e metodologias dos professores de geografia nas séries iniciais. Essa perspectiva pedagógica enrijeceu, de certa forma, o conceito sobre categorias como Lugar e Paisagem, que muitas vezes são apresentadas como realidades dadas e sem conexões com o seu entorno.

Percebendo a rigidez conceitual em torno da "realidade imediata" (ponto de partida) para o raciocínio geográfico nas séries iniciais, Straforini (2004) faz objeção ao que considerou ser um reducionismo explicativo dos conceitos como Lugar, Paisagem e habitat expressos nos conteúdos das séries iniciais:

[...] nosso questionamento centra-se na leitura de que esse imediato concreto, entendido na escola como bairro e/ou a cidade, pouco consegue extravasar seus limites explicativos porque os alunos não são levados a considerar os interesses, as empresas globais, agindo sobre o seu imediato concreto, uma vez que privilegia-se muito mais a forma e a aparência em detrimento do seu conteúdo (STRAFORNI, 2008, p.80).

O autor destacou que, apesar de rica, a proposta do "imediato concreto e da materialidade objetiva do aluno" ela tem uma limitação na escala explicativa que persiste nessa abordagem pedagógica, reverberando também na própria visão de geografia enquanto conhecimento da realidade. Deste modo, se a ciência geográfica tem como selo distintivo o estudo dos arranjos espaciais mediante a identificação das relações entre os diferentes fenômenos, por que então entender o real imediato separado de um contexto mais amplo de relações que a definem e que tem o potencial de desvendar a sua lógica espacial?

O que está posto a questionamento, é proposta de análise fragmentada do espaço geográfico (Figura 1) nas séries iniciais, que introduz os conceitos de Lugar, Paisagem e Região como realidades estanques ou como partes e não articulados. 
Figura 1: Modelo explicativo das dimensões escalares

\begin{tabular}{|c|c|c|c|c|c|c|}
\hline $\begin{array}{c}\text { Bairro Vila Alemã } \\
\text { município de } \\
\text { Rio Claro }\end{array}$ & $\begin{array}{c}\text { Município de } \\
\text { Rio Claro }\end{array}$ & $\begin{array}{c}\text { Município de } \\
\text { Rio Claro na região } \\
\text { de Campinas }\end{array}$ & $\begin{array}{c}\text { Região de } \\
\text { Campinas no Est. } \\
\text { de São Paulo }\end{array}$ & $\begin{array}{c}\text { Estado de São } \\
\text { Paulo no Brasil }\end{array}$ & $\begin{array}{c}\text { Brasil na } \\
\text { América }\end{array}$ & $\begin{array}{c}\text { América no } \\
\text { Mundo }\end{array}$ \\
\hline DA PARTE PARA O TODO &
\end{tabular}

Fonte:Straforini (2004, p.68)

Os conceitos e temas geográficos são trabalhados hierarquicamente em escalas dissociativas, não apresentando o todo articulado dos fenômenos espaciais. Nesse caso, perde-se de vista o que é de fundamental no ensino da geografia: a perspectiva relacional dos acontecimentos e das estruturas na concepção da ordem espacial.

Desta forma, Straforini defende que os conceitos de Lugar, Paisagem e Região seja trabalhado de forma que eles evoquem na mente do aluno uma totalidade-mundo (Figura 2) e não como categorias que se encerram em si mesmas. 
Figura 2: Modelo Explicativo Das Dimensões Escalares: Totalidade-Mundo

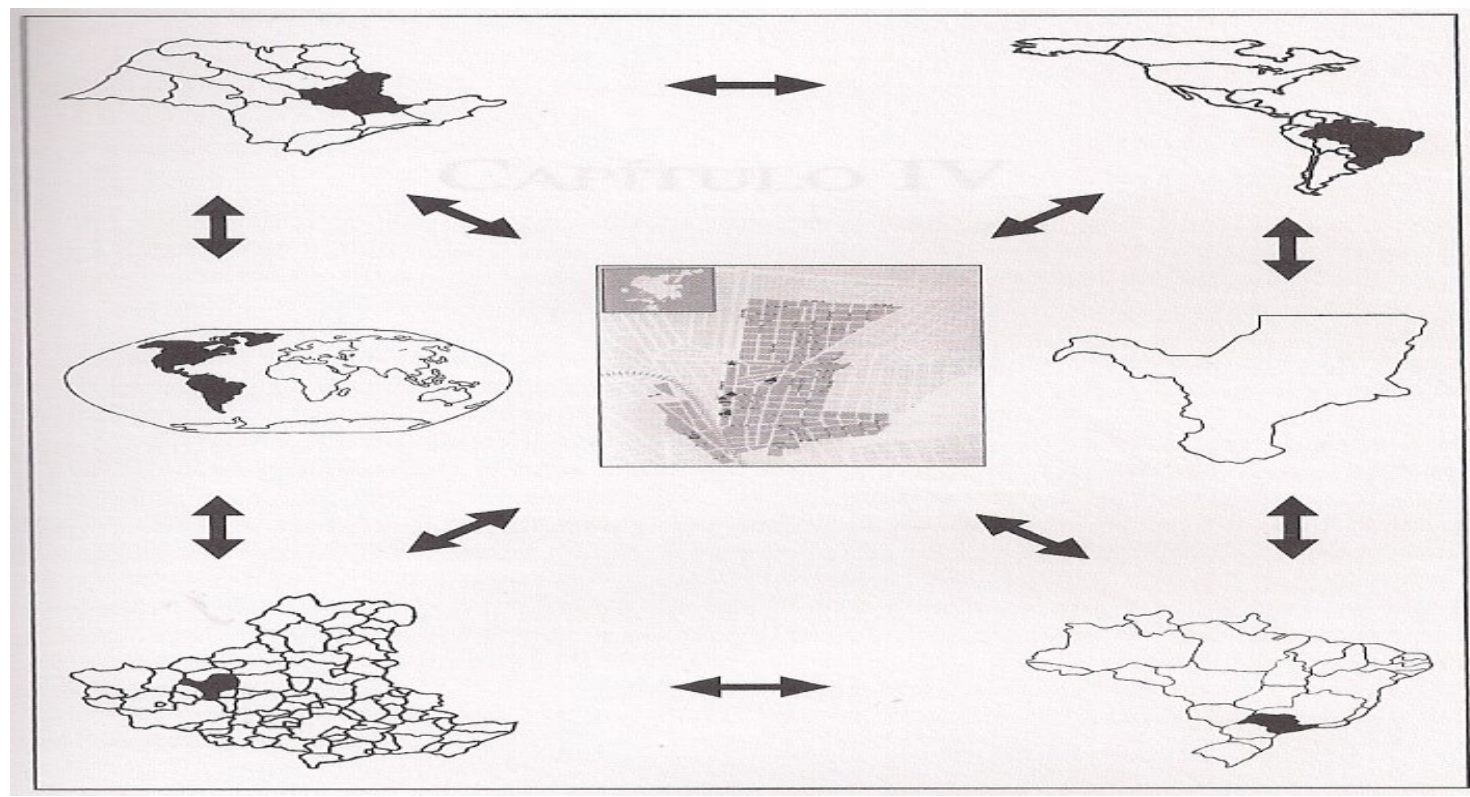

Fonte:Straforini (2004, p.95)

A ideia da totalidade-mundo mostra o quanto devemos atentar para a compreensão dos eventos globais e como suas formas mais visíveis e concretas se realizam e são materializadas no lugar. O termo totalidade-mundo, aproxima-se da análise de Santos quando esse discutiu a ideia $d a$ totalidade ao lugar, "[...] em que nenhuma questão pode ser respondida fora de uma totalidade de estruturas e de uma totalidade de relações" (SANTOS, 2012, p.490).

Julgamos ser prudente discorrer sobre a ideia da relação entre o local e o global, sem alterar suas estruturas conceituais conservando a proposição dos autores supracitados. Contudo, ao invés da totalidade-mundo simplesmente, é importante entender o "lugar na Totalidade-mundo". Isso inevitavelmente pressupõe analisarmos também, as relações da Paisagem na totalidade-mundo, a Região na totalidade-mundo como sistemas integrados precariamente ou não às lógicas globais.

Analisar a Paisagem na totalidade-mundo, é compreender que a morfologia ou design das paisagens é resultado de fluxos globais que se entrelaçam em níveis diferenciados. Essa proposta tem como propósito subsidiar conceitualmente o desenvolvimento de metodologias de ensino que ajudem efetivamente os alunos a compreenderem melhor a complexidade inerente ao mundo globalizado.

O uso das redes de informacionais, a exemplo disso, se tornou parte essencial e irredutível no cotidiano dos alunos para realização de variadas atividades. Portanto, não é somente as exigências teórico-metodológicas da geografia, mas à própria realidade que os põem diante de uma rede infinita 
de relações. O estudo da Paisagem na totalidade-mundo nas séries iniciais é, portanto, possível quando,

\begin{abstract}
[...] o espaço global for redimensionado para sua concretude, que não está no mundo, mas no lugar/paisagem/região. Encontrar esses elementos globais no lugar e estabelecer as relações do próximo com o longínquo pode levar a criança a desvendar ou elaborar novas indagações sobre o mundo (...) trabalhar a realidade dos alunos sem se prender apenas aos limites administrativos do bairro e do município, embora esses conceitos políticos-administrativos sejam importantes (...) trabalhar o próximo, abre o caminho para encontrar as ações e as intenções que são tomadas fora do lugar, possibilitando, desta forma, contatar outros lugares, enfim, o mundo (STRAFORINI, 2002, p.97).
\end{abstract}

A importância de se trabalhar metodologias que evidenciem a Paisagem na totalidademundo, como locus da reprodução da globalização, justifica-se nos avanços epistemológicos recentes dos estudos de Sack (1986); Raffestin (1993); Haesbaert (2004); os quais demandam o estudo sobre como as redes vêm alterando a ordem e as engrenagens do macrossistema global e consequentemente como interferem na construção do saber Geografia.

Na geografia humana, o estudo da produção e do consumo instantâneo de produtos e informações que partem das mais diferentes localizações do globo é trabalhado no temário da Geografia Urbana-regional. Assim, é pertinente pensar a lógica do Lugar, da Paisagem e da Região interligada à rede de fluxos informacionais que provocaram o questionamento da linearidade das velhas hierarquias urbanas e dos limites territoriais.

Na geografia física, a teoria dos Geossistemas de Robert Christopherson (2012) também avança na abordagem da Paisagem na totalidade-mundo, quando apresentou a interconexão das diferentes subunidades geossistêmicas, como Atmosfera (Sistema energia-ambiente), Hidrosfera (os sistemas hídricos, do tempo meteorológico e climático), a Litosfera (a interface Terra-atmosfera) e a Bioesfera (solos, ecossistemas e biomas) na transformação e diferenciação das paisagens na superfície terrestre.

As metodologias comungadas ao modelo explicativo das categorias geográficas, associadas ao sistema global, começam a tomar forma quando superamos a limitação da análise reducionista e visualizamos o Lugar, a Paisagem, o Território e a Região enquanto instâncias inseparáveis de um sistema global, seja na condição de protagonista ou de coadjuvante.

Neste contexto, os Geocenários Digitais assumem um papel importante na metodologia do professor frente às demandas por uma análise da Paisagem na totalidade-mundo.

Primeiro, enquanto metodologia, os Geocenários Digitais ambientam o aluno no universo das redes informacionais, entre eles, como posto anteriormente, temos os arquivos digitais, 
compartilhamento instantâneo de dados, acesso remoto em diferentes dispositivos móveis, interatividade em rede, entre outros feitos, para difundir globalmente o conhecimento produzido pelos alunos.

Segundo, pela maneira singular é possível produzir um conhecimento contínuo e colaborativo para além da sala de aula, longe das limitações locacionais previstas na modalidade presencial de ensino. Além disso, a colaboração entre os alunos em projetos e atividades de ensino para além da sala de aula é uma das qualidades dos Geocenários Digitais. Os arquivos gerados no Software Google Earth Pro podem ser compartilhados em nuvem, refeitos, e compartilhados em uma nova versão permitindo o aprendizado contínuo e aperfeiçoamento investigativo dos alunos.

Para a produção dos Geocenários Digitais, o Google Earth Pro é apresentado como um dos geosoftwares mais completos e eficientes. Enquanto um geosoftware de livre acesso disponível na internet, possui recursos exclusivos que o torna único na representação e interatividade na montagem de cenários geográficos.

Para o desenvolvimento dos Geocenários Digitais de maneira experimental, foi organizado um curso de extensão "Geocenários Digitais para o ensino da Geografia” com professores da Rede Municipal de Educação da cidade de Currais Novos/RN, entre os meses de out5ubro e novembro de 20219 durante 4 (quatro) semanas, este curso foi aprovado pelo Departamento de Geografia da Universidade Federal do Rio Grande do Norte e pela Secretaria Municipal de Educação de Currais Novos/RN.

O curso foi estruturado em módulos: Módulo I - Apresentação do Google Earth Pro e seus recursos didático pedagógico; Módulo II - A Paisagem e suas transformações: o Geocenário Digital de Currais Novos/RN; Módulo III - Geocenários Digitais: os passos para um planejamento didático pedagógico; e Módulo IV - Geocenários Digitais: vivências e experiências. Cada Módulo teve a seguinte estrutura: título, objetivos e desenvolvimento metodológico.

O curso comtemplou a apresentação do Software Google Earth Pro e seus recursos didático pedagógico; análise da paisagem e suas transformações através dos Geocenários Digitais desenvolvidos pelos ministrantes; customização de um Geocenário Digital desenvolvido pelos professores participantes alinhado com suas proposta didática, e por fim, a apresentação e discursão dos resultados obtidos com as experiências em sala de aula.

Para desenvolver um Geocenário Digital, inicialmente apresentamos o Software Google Earth Pro e as ferramentas para se trabalhar uma superfície cartográfica digital com o maior grau de resolução e detalhamento entre os geosoftwares disponíveis hoje na web. Diferente das imagens 
estáticas dos livros, esse geosoftware dispõe de imagens de satélite georreferenciadas com representação do globo em projeção plana ou polar.

Com o recurso do Zoom disponível no Google Earth Pro é possível ampliar os detalhes e visualizar a elevação do terreno tanto da geomorfologia em diferentes regiões naturais como dos edifícios nos espaços urbanos. Os objetos geográficos representados pelo Google Earth Pro podem ser visualizados em diferentes escalas cartográficas em 2D e 3D (Figura 3) tornando a navegação ainda mais realística para os usuários.

Figura 3 - Imagens 3d Google Earth: Av. Paulista (sp) e monte Fuji (Japão)
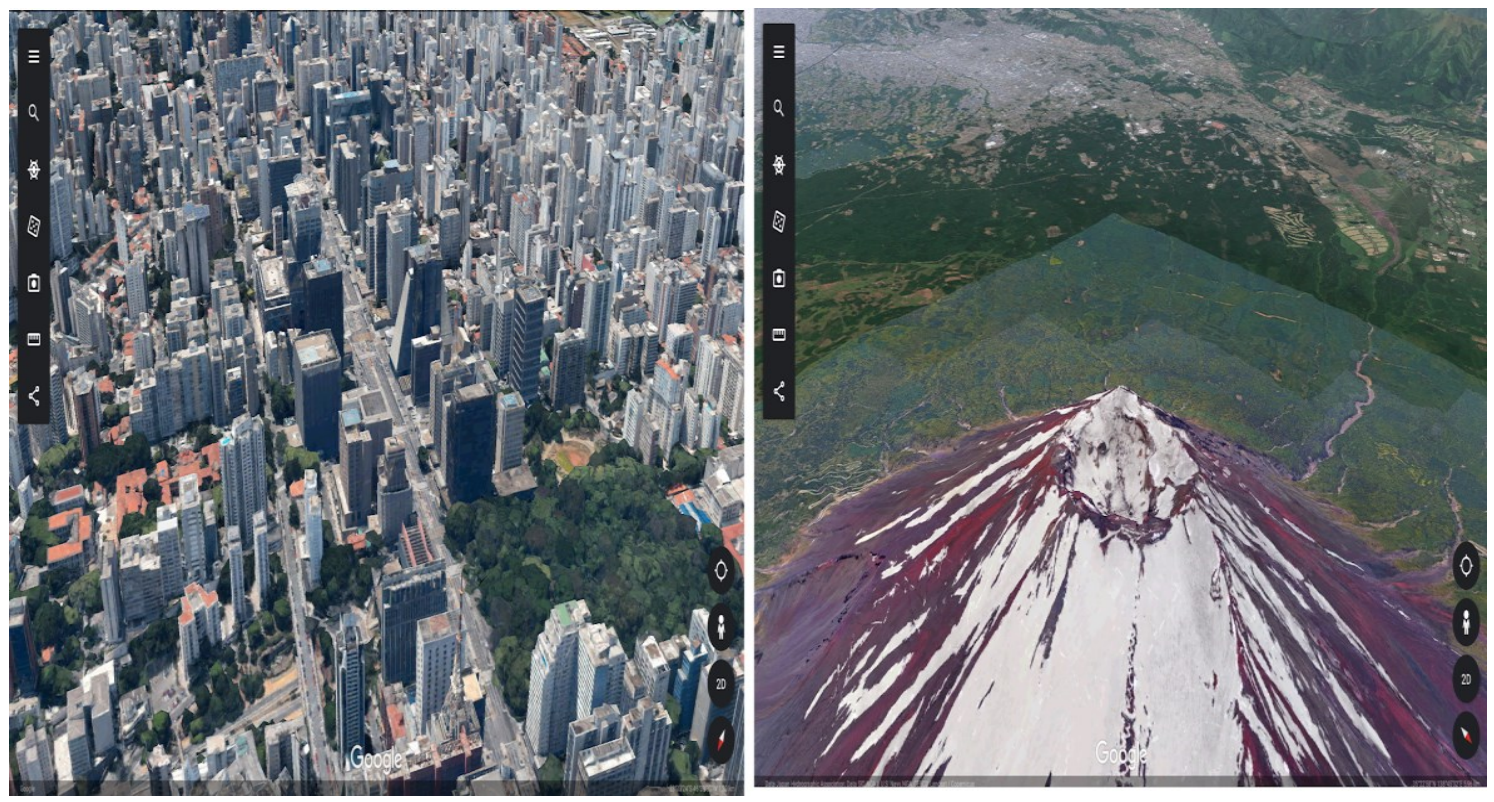

Fonte:Google Earth (2020)

A metodologia de construção dos Geocenários Digitais está alicerçada na perspectiva da Paisagem na totalidade-mundo, e dessa forma, contribui para o entendimento da geografia, como ciência das conexões espaciais, ou seja, onde o fenômeno geográfico jamais acontece isoladamente (Figura 4), mas na interação com outros fenômenos em escala global. 
Figura 4 - Impacto ambiental do esgoto local e sua relação com a bacia hidrográfica do Açu-Piranhas/RN

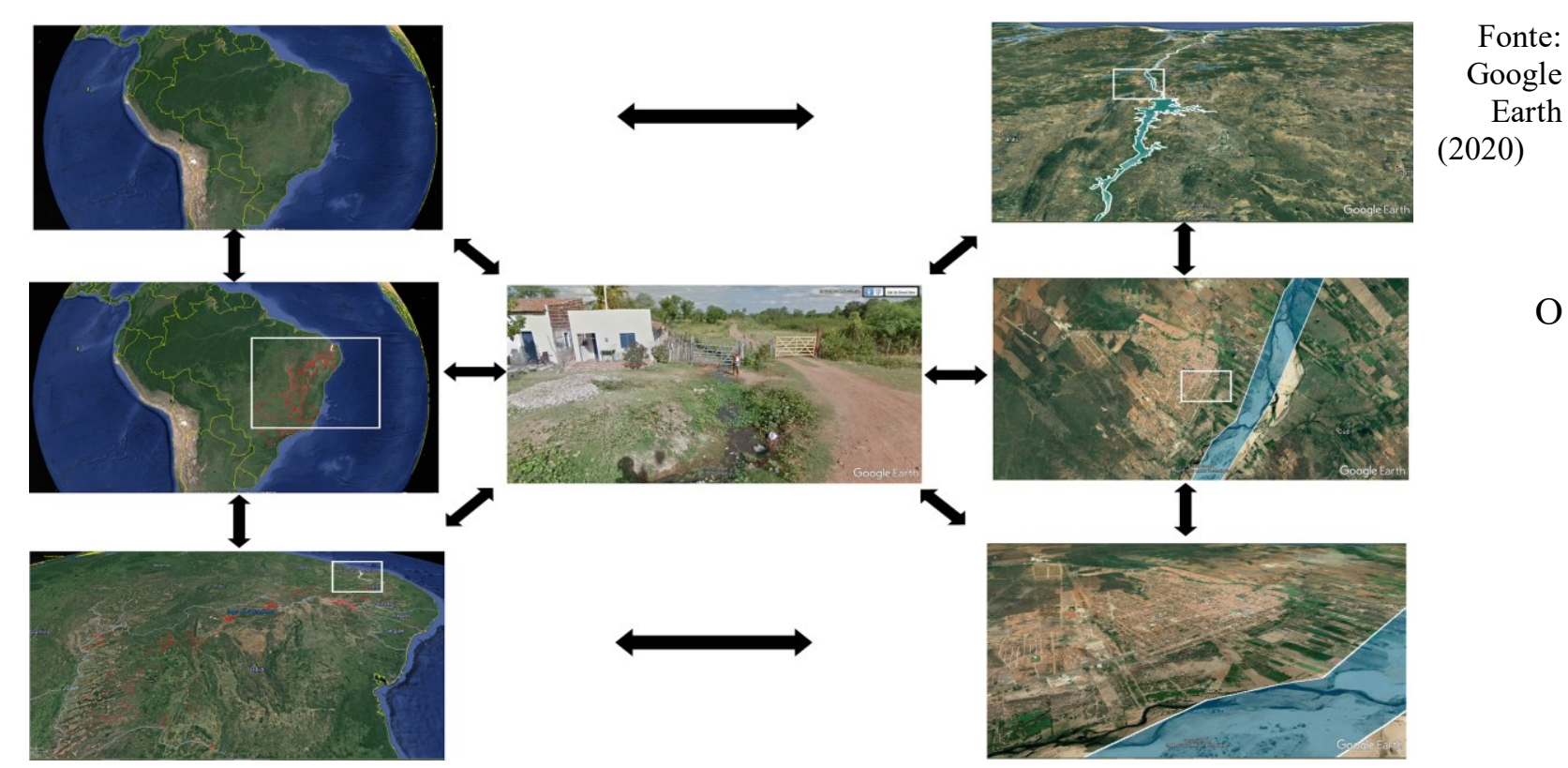

Geocenário Digital acima é a representação esquemática de um impacto ambiental na bacia hidrográfica do Açu-Piranhas/RN desenvolvido ao longo do curso de extensão. Neste Geocenário foi possível discutir a perspectiva do lugar e da paisagem na totalidade-mundo, na qual foi possível desenvolver a relação entre as imagens que fazem referência a falta de saneamento (imagem central) e sua contribuição para a promoção do impacto ambiental em diferentes escalas geográficas e cartográficas. Utilizando os recursos do Software, "importação de shapers" e "polígonos”, foi possível destacar toda a Bacia Hidrográfica do Piancó-Piranhas-Açu/RN e delimitar extensão do impacto ambiental e da urbanização na Paisagem do semi-árido nordestino.

A partir dessas etapas, temos uma metodologia de representação dinâmica de processo no espaço geográfico, com o potencial de colaborar com o aluno a relacionar fatos, descrever amplamente objetos e compreender a dinâmica da Paisagem dentro de um contexto físico e social específico, como também, suas possíveis conexões com outros espaços ao redor do mundo.

Os recursos presentes no Google Earth Pro permitem produzirmos polígonos para destacar a extensão regional de um determinado fenômeno e analisar detalhadamente os fatores sociais e naturais envolvidos na sua estruturação.

Neste outro Geocenário Digital que trata da Bacia do Rio Prata que se estende pelas áreas fronteiriças do Brasil, Uruguai, Paraguai e Argentina é um importante elemento de integração 
regional que pelas suas áreas de navegação contribui para dar sustentação à dinâmica comercial várias cidades fixadas a sua margem (FIGURA 5).

Figura 5 - Bacia do Rio da Prata (Paraguai-Uruguai)

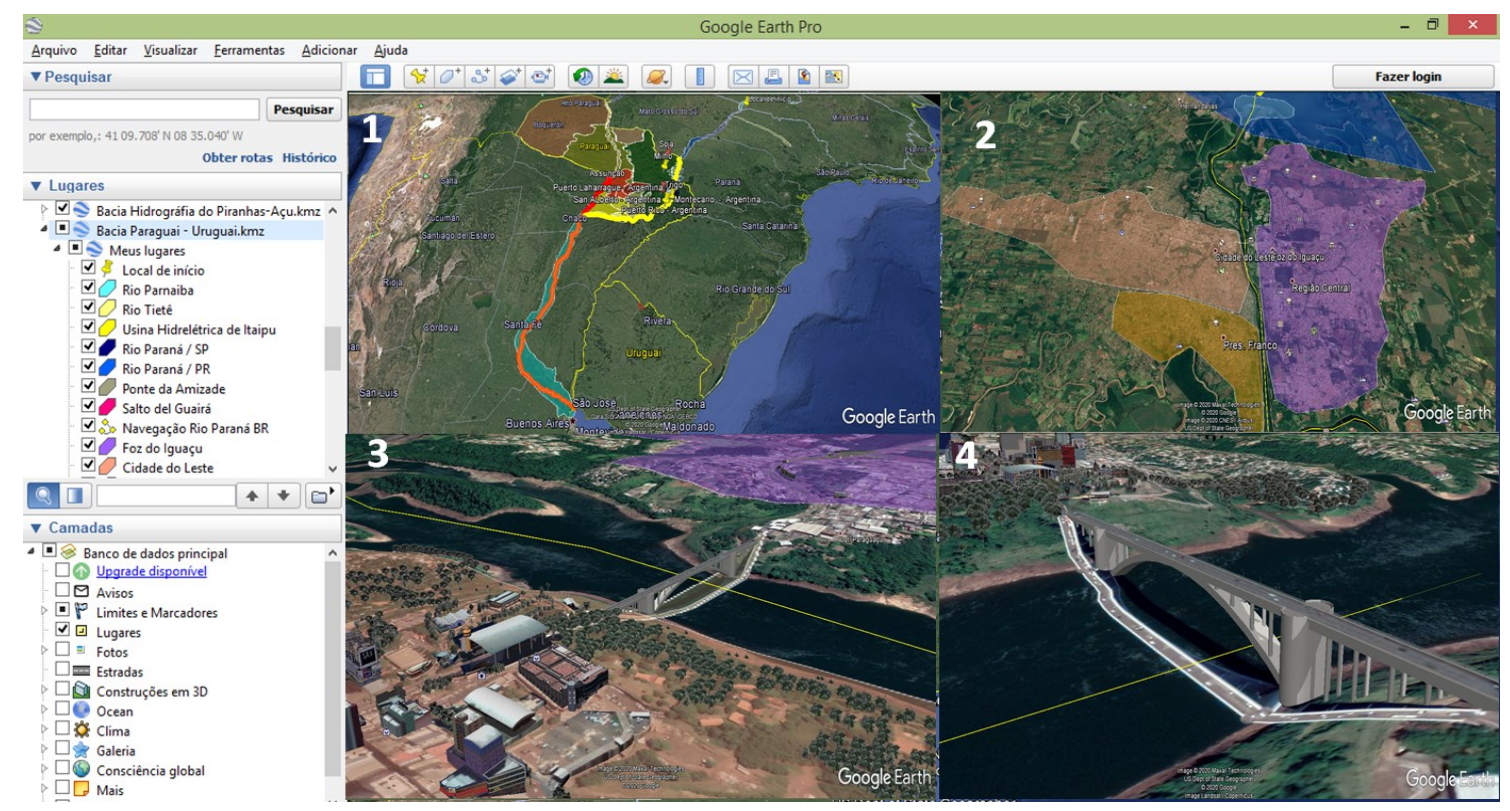

Fonte:Google Earth (2020)

Os Geocenários Digitais personalizados a partir do ambiente cartográfico digital do Google Earth Pro acrescentam interatividade, multiescalaridade e tridimensionalidade para o estudo da dinâmica urbana, o fluxo internacional do comercio e as atividade agrícolas em torno da Bacia do Rio da Prata.

Neste Geocenário Digital (1), foram adicionados marcadores, polígonos e caminhos, todos georreferenciados, que delimitam a área de estudo entre o Brasil, Paraguai e Uruguai. No Geocenário (2) temos a delimitação da mancha urbana que margeia o trecho do Rio da Prata entre a Cidade do Leste - Paraguai e Foz do Iguaçu - Brasil.

Nos Geocenários (3) e 4 foi destacado, em duas escalas diferentes, a principal estrutura de interligação entre Brasil e Paraguai, isto é, a Ponte da Amizade. Aproximando a paisagem em Zoom, é possível reconhecer a ponte sob o Rio da Prata como objeto técnico, que estrutura ligações e fluxos cotidianos possibilitando a realização de atividades de trabalho e estudo, sendo esse o principal elo geográfico entre estes dois países.

A representação da Bacia do Rio da Prata na metodologia dos Geocenários Digitais permite produzir sucessivas análises diminuindo e aumentando o Zoom de cada superfície cartográfica delimitada. Desta forma, utilizando as imagens de satélite do Google Earth Pro, o professor poderá explorar cada elemento da Paisagem com resolução e detalhamento superior à de qualquer livro 
didático, como também, comparar a estrutura urbana das cidades gêmeas, observar impactos ambientais decorrentes do crescimento das aglomerações urbanas adjacentes, georreferenciar os pontos dos afluentes que articula bacia hidrográfica e suas relações com outros níveis de superestrutura regional e global.

Os Geocenários Digitais articulam vários níveis de escalas da Paisagem, seja ela regional e/ou global e complementando os livros didáticos no alcance dos objetivos de ensino. As figuras e ilustrações gráficas dos livros didáticos, geralmente, apresentam escala única, o que reduz as chances de compreensão sistemática e relacional dos processos que ali são descritos.

Os Geocenários Digitais, como demonstrado, avançam na representação tridimensional, multiescalar e interativa dos objetos geográficos na sala de aula. Neste sentido, os Geocenários Digitais atentam para os fundamentos psicopedagógicos presentes na evolução do raciocínio geográfico mediante a proposição de compreender o fenômeno estudado, em suas diferentes escalas e interações na Paisagem. Esse modelo didático de estudo da Paisagem evidência, portanto, o protagonismo das novas tecnologias avaliando as concepções teóricas pertinentes e os resultados práticos da sua utilização em sala de aula.

Por fim, a perspectiva de estudos dos fenômenos em diferentes escalas dos Geocenários Digitais objetiva contribuir de forma incisiva para a construção do conhecimento sobre as relações existentes entre cada elemento da Paisagem. Os Geocenários Digitais favorecem novos horizontes metodológicos para o desenvolvimento de uma análise multiescalar, como para uma didática indutiva (do particular para o geral) a qual direciona os alunos para o entendimento da Paisagem começando por conteúdos procedimentais mais elementares que despertem o interesse do aluno pelo concreto do "Lugar", para sua posterior evolução analítica ao nível das abstrações entre o local e o global.

\section{CONCLUSÃO}

Os Geocenários Digitais foram analisados a partir da sua perspectiva teórica, conceitual e metodológica para fins didáticos, onde foi destacado o seu potencial pedagógico para o desenvolvimento de uma análise das interconexões de fenômenos sociais e físico da Paisagem. A possibilidade de representação de fenômenos na base cartográfica digital do Google Earth Pro confere aos Geocenários Digitais uma perspectiva ensino-aprendizagem interativa e colaborativa baseada na perspectiva da Paisagem na totalidade-mundo onde o fenômeno não é visto isoladamente, mas como o encadeamento de processos em escala regional ou global. 
Como recurso didático para o ensino da Geografia, possibilita aos professores e alunos a leitura e interpretação multiescalar dos fenômenos, o que é imprescindível para a compreensão das conexões entre os diferentes geossistemas e os fenômenos geograficos.

Quanto aos objetivos de ensino, a proposta dos Geocenários Digitais tem o cuidado de alinharse às demandas de desenvolvimento de habilidades e competências da Base Nacional Comum Curricular (BNCC).

Os Geocenários é um recurso didático que não exclui, mas complementa o uso do livro didático e insere o planejamento das atividades de ensino na perspectiva das novas tecnologias da informação e comunicação.

Na perspectiva da pesquisa no ensino da Geografia, o estudo e a utilização dos Geocenários Digitais para o alcance dos objetivos de ensino- aprendizagem ultrapassam a geografia escolar e oferecem um amplo campo de estudos voltados também para pesquisa e desenvolvimento de metodologias para o ensino da Geografia.

Por fim, a produção deste ensaio complementar sobre os Geocenários Digitais objetiva avançar também nas práxis pedagógicas da Geografia, bem como, no estímulo à interdisciplinaridade e à criatividade nas construções do raciocínio geográfico. Podemos perceber claramente o potencial dos Geocenários Digitais para entender os fenômenos geográficos e aprimorar o processo de ensinoaprendizagem na educação básica.

\section{REFERÊNCIAS}

BRASIL. Base Nacional Comum Curricular. Educação é a Base. Brasília, MEC/CONSED/UNDIME, 2017. Disponível em:< http://basenacionalcomum.mec.gov. br/images/BNCC_publicacao.pdf $>$. Acesso em: 27 jan. 2020.

BRASIL. Parâmetros Curriculares Nacionais. Geografia. Ensino Fundamental. Primeiro e segundo ciclos. Brasília: MEC/SEF, 1998.

BRITO, Francisco Jorge de Oliveira; HETKOWSKI, Tânia Maria, [et. al]. (orgs.). Geotecnologias: possibilidades de inclusão. Curitiba: Imprensa Oficial, p. 62-76, 2010.

CARVALHO, Vânia Maria Salomon Guaycuru de. Sensoriamento Remoto no ensino básico da geografia: definindo novas estratégias. UFRJ- Rio de Janeiro, 2006. 284p. Disponível em: <www.ppgg.igeo.ufrj.br/index.php?option=com_docman\&task=doc>. Acesso em: 16 abr. 2020.

CHRISTOPHERSON, Robert W. Geossistemas - Uma introdução à geografia física. Tradução: Francisco Eliseu Aquino ... (et al.). Porto Alegre: Bookman, 7ª edição, 2012.

DI MAIO, Angélica Carvalho. Geotecnologias Digitais no Ensino Médio: avaliação prática de seu potencial. 2004. Tese. Universidade Estadual Paulista, Instituto de Geociências e Ciências Exatas, Rio Claro, São Paulo, 2004. 
FERREIRA, Ercilia Mendes. Geotecnologia como recurso didático para professores de geografia no ensino fundamental da Rede Estadual de Mato Grosso do Sul. Dissertação. Universidade Federal de Mato Grosso do Sul. Aquidauana, MS, 2017.

HAESBAERT, Rogério. O mito da desterritorialização: do "fim dos territórios" à multiterritorialidade. Rio de Janeiro: Bertrand Brasil, 2004.

HONG, Jun Eun. Web-based GIS for middle school teachers: using online mapping applications to promote teacher adoption. 2012. 257 f. Tese. Departament of Geography, University of Colorado, Colorado, 2012.

LONGLEY, Paul. [et al]. Sistemas e ciência da informação geográfica. Porto Alegre: Bookman, 2013.

MARTINS NETO, Antonio Virginio. Geocenários Digitais: uma abordagem inovadora para o ensino da Geografia. 2020. 147 f. Dissertação. Instituto Metrópole Digital, da Universidade Federal do Rio Grande do Norte, Natal, Rio Grande do Norte, 2020.

MORAES, Antonio Carlos Robert. Geografia: pequena história crítica. 20. ed. São Paulo. Annablume, 2005.

OLIVEIRA, Lívia. Uma Leitura Geográfica da Epistemologia do Espaço segundo Piaget. 1. ed. Rio de Janeiro: Bertrand Brasil, v. Único, p. 163-18, 2007.

PONTUSCHKA, Nidia Nacib; PAGANELLI, Tomoko Iyda; CACETE, Núria Hanglei. Para Ensinar e Aprender Geografia. São Paulo: Cortez, 2007.

RAFFESTIN, Claude. Por uma geografia do poder. São Paulo: Ática 1993.

SACK, Robert. Human Territoriality: its theory and history. Cambridge: University Press, 1986.

SANTOS, Milton. Da totalidade ao lugar. São Paulo: EDUSP, 2012.

SIMELLI, Maria Elena. R. Cartografia no ensino fundamental e médio. 8. ed. São Paulo: Contexto, 2018.

SOUSA, Iomara Barros de. A formação continuada de professores de Geografia em geotecnologias aplicadas à Cartografia: experiência de Pesquisa-Ação Pedagógica (PAPe) no Ensino Fundamental II. Tese. Instituto de Geociências e Ciências Exatas do Campus de Rio Claro, da Universidade Estadual Paulista- Júlio de Mesquita Filho, Rio Claro, São Paulo, 2018.

STRAFORINI, Rafael. Ensinar Geografia: o desafio da totalidade-mundo nas séries iniciais. 1. ed. São Paulo: Annablume, v. 1, 188p, 2004.

STRAFORINI, Rafael. A totalidade mundo nas primeiras series do ensino fundamental: um desafio a ser enfrentado. Terra livre, São Paulo, SP, ano 18, vol 1, n. 18, p. 95-114, 2002. 